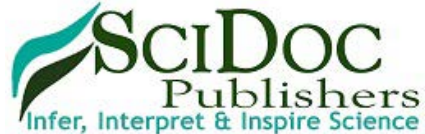

\section{Awareness About the Specialty of Oral and Maxillofacial Surgery among the Medical Fraternity in South India: A KAP Survey}

\section{International Journal of Dentistry and Oral Science (IJDOS) ISSN: $2377-8075$}

Research Article

Dyna Albert ${ }^{1 *}$, MR Muthu Sekhar ${ }^{2}$

${ }^{1}$ Post Graduate Student, Deparment of Oral and Maxillofacial Surgery, Saveetha Dental College, 162, Poonamallee High Rd, Velappanchavadi, Chennai, Tamil Nadu 600077, India.

${ }^{2}$ Director of Programme, Deparment of Oral and Maxillofacial Surgery, Saveetha Dental College, 162, Poonamallee High Rd, Velappanchavadi, Chennai, Tamil Nadu 600077, India.

\title{
Abstract
}

Introduction: Oral and maxillofacial surgery (OMFS) is one of the oldest specialties of dentistry and is often considered as a bridge between medicine and dentistry. Yet, the specialty is less popular among both the general public and the non-dental healthcare professionals when compared to other surgical specialties.

Methodology: A questionnaire survey was conducted to better understand the knowledge, attitude and practice of medical professionals with respect to the specialty of OMFS in South India. It included 19 questions exclusive of demographic data and 202 medical students and practitioners participated in the survey.

Results: Majority of the participants acknowledged the expertise of an OMF surgeon in performing routine dentoalveolar procedures and treating maxillofacial trauma while they were skeptical about the surgeon's ability to perform other supposedly complex procedures. Their overall awareness about the specialty was low.

Conclusion: It is not only important to educate the general public about the specialty but also promote the scope of OMFS among other healthcare communities and establish an unprejudiced understanding and recognition of each specialty's contribution in healthcare.

Keywords: Awareness; Oral and Maxillofacial Surgery; Medical Fraternity; Medical Professionals.

\section{Introduction}

The roots of Oral and maxillofacial Surgery (OMFS) is a very deep one dating back to the genesis of medicine and surgery itself, with the literary works of Hippocrates, Aristotle and Sushruta describing dental extractions and wiring techniques for maxillofacial fracture management [1, 2]. Thoma in his 1957 paper titled "History of Oral Surgery; the Oldest Specialty of Dentistry" nonchalantly mentions the disinterest of many medical practitioners during the 19th century to treat diseases and conditions of the oral cavity due to their non-urgent or not-so-life-threatening nature and also, the possibility of a resultant facial deformity which would leave the operator open to criticism [3]. The fairly limited pursuers who dared to treat conditions of the mouth laid the foundations to the specialty which would later be named as Oral Surgery by James E Garretson and subsequently to Oral and Maxillofacial Surgery in
1975 by the American Association [3, 4]. Yet, even with the contributions of many eminent surgeons in the field who have strived to provide a better understanding of the specialty, till today the specialty of OMFS remains a debatable one which is evident in the difference in its training pathway around the world [5]. Additionally, there is a grayness that exists among the general public and the health professionals in the understanding of the specialty $[6,7]$. Farooq et al., in 2013 described OMFS as a lost tribe and noted the lack of awareness among the general public about the specialty of OMFS due to its shared anatomical areas of interest with other specialties like Plastic Surgery and Ear Nose and Throat (ENT) Surgery [8]. Subashraj K et al in 2008 also mentioned a similar ignorance towards the specialty among the medical communities in comparison to the dental communities [?].

Though the scope of the specialty is vast, beginning humbly from

\footnotetext{
*Corresponding Author:

Dyna Albert,

Post Graduate Student, Deparment of Oral and Maxillofacial Surgery, Saveetha Dental College, 162, Poonamallee High Rd, Velappanchavadi, Chennai, Tamil Nadu 600077, India. Tel: +916380742675

E-mail:dyn.albrt@gmail.com

Received: September 18, 2020

Accepted: October 07, 2020

Published: November 12, 2020

Citation: Dyna Albert, MR Muthu Sekhar. Awareness About the Specialty of Oral and Maxillofacial Surgery among the Medical Fraternity in South India: A KAP Survey. Int J Dentistry Oral Sci. 2020;7(11):1027-1031. doi: http:// dx.doi.org/10.19070/2377-8075-20000203
}

Copyright: Dyna Albert ${ }^{\circ}$ 2020. This is an open-access article distributed under the terms of the Creative Commons Attribution License, which permits unrestricted use, distribution and reproduction in any medium, provided the original author and source are credited. 
dental extractions to more complex craniofacial and microvascular procedures, most of the OMF surgeons restrict their practice to minor oral surgeries due to the shortage in opportunity as the anatomy of interest is being overlapped with other medical specialties $[10,12]$. This is also attributed to the relative recentness of the specialty compared to other surgical fields and also the traditional hesitance to correlate dentistry with surgery which exists among the general public and the medical practitioners [13]. Some countries have attempted to resolve this hesitation by pedestalling OMFS as a specialty which requires both medical and dental degrees but less successfully so, as the grayness among the general public and medical fraternity continues to exist. The problem is only further escalated in developing countries like India [5, 8-14].

Nonetheless, as partners in providing healthcare to the patients, it would only be fair for the medical and dental fraternities to function together and recognise the contribution of the other without prejudice [15].

In this study, we aim to assess the awareness of the specialty of OMFS among the medical fraternity in South India in an attempt to better understand the current scenario in South India.

\section{Methodology}

The proposed survey was conducted after receiving the approval from the University Institutional Review Board.

\section{Study Design}

To understand the awareness of the medical professionals about the specialty of oral and maxillofacial surgery with respect to knowledge, attitude and practice, an electronic survey was conducted using an online portal which was distributed in the form of a web link. Clicking on the link led users to an online structured questionnaire written in English consisting of 19 questions excluding the demographic data. For convenience sake, the questions were categorised into the following: (1) Demographic data (2) Knowledge about the specialty of oral and ,maxillofacial surgery (3) Attitude towards the specialty of oral and maxillofacial surgery (4) Practice ideologies of the medical professionals with respect to the specialty of oral and maxillofacial surgery. The questions were framed in multiple choice format and the respondents were asked to choose the most appropriate response. An individual could only submit the form once and their response was non-modifiable after submission. The participation was vol- untary and anonymous.

\section{Inclusion Criteria}

Only medical practitioners and students pursuing medicine at the time of survey were included in the study

\section{Exclusion Criteria}

Medical students in their first or second year of study who were not sufficiently exposed to the clinical environment were excluded from the study in an attempt to avoid bias.

\section{Data Collection and Statistical Analysis}

The survey responses were tabulated in Excel Datasheet and was statistically analysed with SPSS Version 20 Software using descriptive statistics while the strength of association was measured using Pearson's Chi Square Test at Confidence Interval (CI) 95\% where $\mathrm{p}<0.05$ was considered statistically significant.

\section{Results}

A total of 207 responses were collected of which 5 responses were excluded, due to incompletion of the form. The remaining 202 responses were assembled and included in the study. Of the participants, $32.18 \%$ were undergraduate medical students, $28.22 \%$ were postgraduate medical students, $21.19 \%$ were general physicians and $18.32 \%$ were specialist practitioners (Fig 1).

The non-demographic questionnaire responses were grouped, analysed and interpreted as follows:

\section{Knowledge (Table 1)}

These questions assessed the knowledge of the participants about the specialty of oral and maxillofacial surgery.

Among the participants, only $71.3 \%$ were aware of the different specialties in dentistry while $28.7 \%$ were ignorant of it. When asked if they were aware of a specialty called OMFS, only $70.3 \%$ of them responded positively while $29.7 \%$ of them gave a negative response. Of the participants, $55 \%$ of them professed to be aware of the different procedures done in OMFS while $45 \%$ of them were unaware. Moreover, only $34.7 \%$ of them were aware of the different training pathways in OMFS while $65.3 \%$ of them were

Figure 1. Pie chart showing the distribution of the participants with respect to their designation.

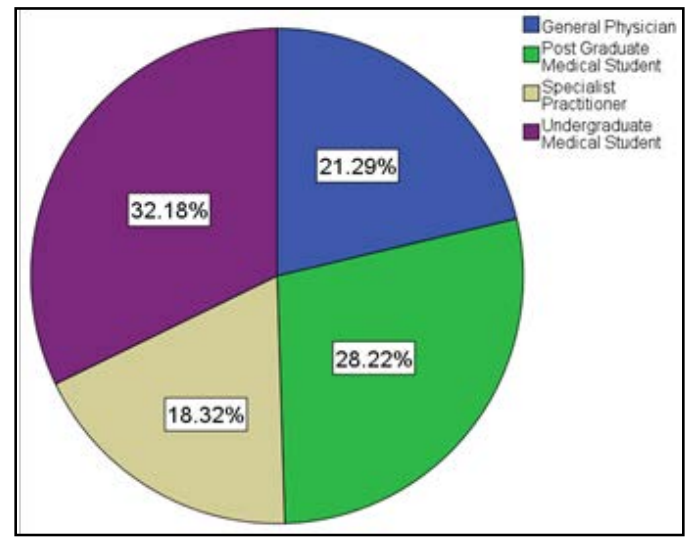


still ignorant of the same. Only $53 \%$ of the participants seemed to know that OMFS was not restricted to dentoalveolar surgeries while $47 \%$ had a misconception that OMFS only pertains to dentoalveolar surgeries. The association between the designation of the participants and their knowledge about the specialty of Oral and Maxillofacial Surgery is illustrated in Table 1 where $p<0.05$ at CI $95 \%$ is considered to be statistically significant.

\section{Attitude (Table 2)}

These questions assessed the attitude of the participants towards the specialty of oral and maxillofacial surgery.

Among the participants, $51 \%$ of them thought that OMF surgeons were qualified to perform procedures other than dentoalveolar surgeries while $49 \%$ of them thought otherwise. Expectedly, $67.8 \%$ of the participants thought that all surgical branches including OMFS should be a specialty of medicine while $32.2 \%$ of them did not think so. The question "Which of the following do you think OMFS surgeons are qualified to manage/treat/ perform?" had 9 sub-questions ranging from extraction of teeth to microvascular surgeries. $93.7 \%$ of the participants believed that OMF surgeons were qualified to perform extraction of teeth and third molar surgeries while interestingly $6.3 \%$ of them did not believe so. Pertaining to placement of dental implants, $90.1 \%$ of them believed an OMF surgeon was qualified to perform the procedure while $9.9 \%$ of them did not think so. The opinion of the participants was split with regard to cleft lip and palate surgeries, TMJ surgeries and cosmetic surgeries. That is, of all the participants only $46.5 \%, 53 \%$ and $41.6 \%$ of them believed that an OMF surgeon was qualified to perform cleft lip and palate surgeries, TMJ surgeries and cosmetic surgeries, respectively. With regard to surgeries to treat craniofacial anomalies, only $29.2 \%$ of the participants thought an OMF surgeon was qualified to perform the procedure while $70.8 \%$ did not think so. Furthermore, only $28.2 \%$ and $33.7 \%$ of the participants considered an OMF surgeon qualified to perform head and neck cancer and microvascular surgeries respectively. The association between the designation of the participants and their attitude towards the specialty of Oral and
Maxillofacial Surgery is illustrated in Table 2 where $\mathrm{p}<0.05$ at CI $95 \%$ is considered to be statistically significant.

\section{Practice (Table 3)}

These questions assessed the practice of the participants with respect to the specialty of oral and maxillofacial surgery

Among the participants, only $59.4 \%$ of them have ever referred a patient to an OMF surgeon and only $43.6 \%$ had referred for reasons other than dentoalveolar surgeries. $61.4 \%$ of the participants said that they will refer patients to an OMF surgeon for reasons other than dentoalveolar surgeries in the future. The association between the designation of the participants and their attitude towards the specialty of Oral and Maxillofacial Surgery is illustrated in Table 3 where $\mathrm{p}<0.05$ at CI $95 \%$ is considered to be statistically significant.

\section{Discussion}

A surgeon trained in OMFS is qualified not only to perform dentoalveolar surgeries but also to surgically manage trauma and pathologies pertaining to craniomaxillofacial region, treat diseases of the temporomandibular joint (TMJ) and perform esthetic procedures of the face inclusive of orthognathic and facial plastic surgeries. With advanced training they can treat developmental conditions of the craniomaxillofacial region with cleft and craniofacial surgeries and perform surgical resection of head and neck tumours followed by reconstruction with either local or microvascular flaps. The training pathways of the specialty are varied in different parts of the world $[11,16]$.

Oral and Maxillofacial Surgery is the only specialty to be regarded as a bridge between medicine and dentistry. But uncannily, the specialty is placed in an obscure ground where the dental fraternity regards them as surgeons and the medical specialty as dentists [17]. In India, the specialty is a part of dentistry, hence a relative popularity of the specialty among the dentists when compared to

Table 1. Participants' responses to the questions assessing their knowledge about the specialty of Oral and Maxillofacial Surgery(* represents the associations which are statistically significant with $\mathrm{p}<0.05$ at $\mathrm{CI} 95 \%$ ).

\begin{tabular}{|c|c|c|c|c|c|c|c|c|c|c|c|c|}
\hline \multirow{2}{*}{ S.No } & \multirow[t]{2}{*}{ Questions } & \multicolumn{2}{|c|}{$\begin{array}{c}\text { Undergraduate Medi- } \\
\text { cal Student }\end{array}$} & \multicolumn{2}{|c|}{$\begin{array}{c}\text { Post Graduate } \\
\text { Medical Student }\end{array}$} & \multicolumn{2}{|c|}{ General Physician } & \multicolumn{2}{|c|}{$\begin{array}{c}\text { Specialist Practi- } \\
\text { tioner }\end{array}$} & \multicolumn{2}{|c|}{ Total Responses } & \multirow[t]{2}{*}{$\mathrm{p}$ value } \\
\hline & & Yes & No & Yes & No & Yes & No & Yes & No & Yes & No & \\
\hline 1 & $\begin{array}{c}\text { Are you aware of the } \\
\text { different specialties in } \\
\text { Dentistry? }\end{array}$ & $21.78 \%$ & $10.40 \%$ & $22.28 \%$ & $5.94 \%$ & $12.87 \%$ & $8.42 \%$ & $14.36 \%$ & $3.96 \%$ & $71.30 \%$ & $28.70 \%$ & 0.144 \\
\hline 2 & $\begin{array}{l}\text { Are you aware of the } \\
\text { specialty of Oral and } \\
\text { Maxillofacial Surgery? }\end{array}$ & $19.80 \%$ & $12.38 \%$ & $23.27 \%$ & $4.95 \%$ & $12.38 \%$ & $8.91 \%$ & $14.85 \%$ & $3.47 \%$ & $70.30 \%$ & $29.70 \%$ & $0.009 *$ \\
\hline 3 & $\begin{array}{l}\text { Are you aware of the } \\
\text { different procedures } \\
\text { done in Oral and Max- } \\
\text { illofacial Surgery? }\end{array}$ & $15.35 \%$ & $16.83 \%$ & $20.79 \%$ & $7.43 \%$ & $7.43 \%$ & $13.86 \%$ & $11.39 \%$ & $6.93 \%$ & $55 \%$ & $45 \%$ & $0.001 *$ \\
\hline 4 & $\begin{array}{c}\text { Are you aware of } \\
\text { the different training } \\
\text { pathways in Oral and } \\
\text { Maxillofacial Surgery? }\end{array}$ & $5.45 \%$ & $26.73 \%$ & $18.32 \%$ & $9.90 \%$ & $4.46 \%$ & $16.83 \%$ & $5.45 \%$ & $12.87 \%$ & $34.70 \%$ & $65.30 \%$ & $0.000^{*}$ \\
\hline 5 & $\begin{array}{l}\text { Are you aware that } \\
\text { Oral and Maxillofa- } \\
\text { cial Surgery is not } \\
\text { restricted to dentoal- } \\
\text { veolar surgeries? }\end{array}$ & $12.87 \%$ & $19.31 \%$ & $20.79 \%$ & $7.43 \%$ & $10.40 \%$ & $10.89 \%$ & $8.91 \%$ & $9.41 \%$ & $53 \%$ & $47 \%$ & $0.002 *$ \\
\hline
\end{tabular}


Table 2. Participants' responses to questions assessing their attitude towards the specialty of Oral and Maxillofacial Surgery (*represents the associations which are statistically significant with $\mathrm{p}<0.05$ at $\mathrm{CI} 95 \%$ ).

\begin{tabular}{|c|c|c|c|c|c|c|c|c|c|c|c|c|}
\hline \multirow[t]{2}{*}{ S.No } & \multirow[t]{2}{*}{ Questions } & \multicolumn{2}{|c|}{$\begin{array}{l}\text { Undergradu- } \\
\text { ate Medical } \\
\text { Student }\end{array}$} & \multicolumn{2}{|c|}{$\begin{array}{l}\text { Post Graduate } \\
\text { Medical Student }\end{array}$} & \multicolumn{2}{|c|}{$\begin{array}{l}\text { General Physi- } \\
\text { cian }\end{array}$} & \multicolumn{2}{|c|}{$\begin{array}{c}\text { Specialist Prac- } \\
\text { titioner }\end{array}$} & \multicolumn{2}{|c|}{ Total Responses } & \multirow[t]{2}{*}{$\mathrm{p}$ value } \\
\hline & & Yes & No & Yes & No & Yes & No & Yes & No & Yes & No & \\
\hline 1 & $\begin{array}{l}\text { Do you think Oral and Maxillofacial } \\
\text { Surgeons are qualified to do procedures } \\
\text { other than dentoalveolar surgeries? }\end{array}$ & $13.37 \%$ & $18.81 \%$ & $21.29 \%$ & $6.93 \%$ & $8.42 \%$ & $12.87 \%$ & $7.92 \%$ & $10.40 \%$ & $51 \%$ & $49 \%$ & $0.000^{*}$ \\
\hline 2 & $\begin{array}{c}\text { Do you think all surgical } \\
\text { branches(including Oral and Maxillo- } \\
\text { facial Surgery) should be a specialty of } \\
\text { medicine? }\end{array}$ & $19.31 \%$ & $12.87 \%$ & $22.28 \%$ & $5.94 \%$ & $15.35 \%$ & $5.94 \%$ & $10.89 \%$ & $7.43 \%$ & $67.80 \%$ & $32.20 \%$ & 0.086 \\
\hline 3 & \multicolumn{12}{|c|}{ Which of the following procedures do you think an OMF surgeon is qualified to perform? } \\
\hline a) & $\begin{array}{c}\text { Extraction of teeth and third molar } \\
\text { surgery }\end{array}$ & $29.70 \%$ & $0 \%$ & $28.22 \%$ & $2.97 \%$ & $20.30 \%$ & $2.48 \%$ & $15.35 \%$ & $0.99 \%$ & $93.60 \%$ & $6.40 \%$ & $0.017 *$ \\
\hline b) & Dental implant placement & $30.20 \%$ & $1.98 \%$ & $26.73 \%$ & $1.49 \%$ & $17.33 \%$ & $3.96 \%$ & $15.84 \%$ & $2.48 \%$ & $90.10 \%$ & $9.90 \%$ & 0.086 \\
\hline c) & $\begin{array}{c}\text { Management of fracture in maxillofacial } \\
\text { region }\end{array}$ & $24.26 \%$ & $7.92 \%$ & $22.77 \%$ & $5.45 \%$ & $13.37 \%$ & $7.92 \%$ & $12.38 \%$ & $5.84 \%$ & $53 \%$ & $47 \%$ & 0.195 \\
\hline d) & Cleft lip and palate surgeries & $13.37 \%$ & $18.81 \%$ & $18.32 \%$ & $9.90 \%$ & $7.43 \%$ & $13.86 \%$ & $7.43 \%$ & $10.89 \%$ & $49.50 \%$ & $53.50 \%$ & $0.010^{*}$ \\
\hline e) & Management of TMJ disorders & $17.33 \%$ & $14.85 \%$ & $17.82 \%$ & $10.40 \%$ & $8.91 \%$ & $12.38 \%$ & $8.91 \%$ & $9.41 \%$ & $53 \%$ & $47 \%$ & 0.187 \\
\hline f) & Cosmetic surgeries of the face & $15.35 \%$ & $16.83 \%$ & $14.36 \%$ & $13.86 \%$ & $5.94 \%$ & $15.35 \%$ & $5.94 \%$ & $12.38 \%$ & $41.60 \%$ & $58.40 \%$ & 0.055 \\
\hline g) & Craniofacial anomalies & $8.42 . \%$ & $23.76 \%$ & $12.87 \%$ & $15.35 \%$ & $2.97 \%$ & $18.32 \%$ & $4.95 \%$ & $13.37 \%$ & $20.20 \%$ & $70.80 \%$ & $0.005^{*}$ \\
\hline h) & Head and neck cancer surgery & $8.42 \%$ & $23.76 \%$ & $13.37 \%$ & $14.85 \%$ & $1.98 \%$ & $19.31 \%$ & $4.46 \%$ & $13.86 \%$ & $28.20 \%$ & $71.80 \%$ & $0.000^{*}$ \\
\hline i) & $\begin{array}{c}\text { Microvascular reconstruction of head } \\
\text { and neck }\end{array}$ & $9.90 \%$ & $22.28 \%$ & $13.86 \%$ & $14.36 \%$ & $5.45 \%$ & $15.84 \%$ & $4.46 \%$ & $13.86 \%$ & $33.70 \%$ & $66.30 \%$ & $0.029 *$ \\
\hline
\end{tabular}

Table 3. Participants' responses to the questions assessing their practice with respect to the specialty of Oral and Maxillofacial Surgery (* represents the associations which are statistically significant with $\mathrm{p}<0.05$ at $\mathrm{CI} 95 \%$ ).

\begin{tabular}{|c|c|c|c|c|c|c|c|c|c|c|c|c|}
\hline \multirow[t]{2}{*}{ S.No } & \multirow[t]{2}{*}{ Questions } & \multicolumn{2}{|c|}{$\begin{array}{l}\text { Undergraduate } \\
\text { Medical Student }\end{array}$} & \multicolumn{2}{|c|}{$\begin{array}{l}\text { Post Gradu- } \\
\text { ate Medical } \\
\text { Student }\end{array}$} & \multicolumn{2}{|c|}{$\begin{array}{l}\text { General Physi- } \\
\text { cian }\end{array}$} & \multicolumn{2}{|c|}{$\begin{array}{c}\text { Specialist Prac- } \\
\text { titioner }\end{array}$} & \multicolumn{2}{|c|}{ Total Responses } & \multirow[t]{2}{*}{$\underset{\text { value }}{\mathrm{p}}$} \\
\hline & & Yes & No & Yes & No & Yes & No & Yes & No & Yes & No & \\
\hline 1 & $\begin{array}{c}\text { Have you ever referred patients } \\
\text { to an Oral and Maxillofacial } \\
\text { Surgeon? }\end{array}$ & $15.35 \%$ & $16.83 \%$ & $21.78 \%$ & $6.44 \%$ & $11.88 \%$ & $9.41 \%$ & $10.40 \%$ & $7.92 \%$ & $59.40 \%$ & $40.60 \%$ & $0.009 *$ \\
\hline 2 & $\begin{array}{l}\text { Have you ever referred patients } \\
\text { to an Oral and Maxillofacial } \\
\text { Surgeon for reasons other than } \\
\text { dentoalveolar surgeries? }\end{array}$ & $10.89 \%$ & $21.29 \%$ & $18.32 \%$ & $9.90 \%$ & $5.94 \%$ & $15.35 \%$ & $8.42 \%$ & $9.90 \%$ & $43.60 \%$ & $56.40 \%$ & $0.001 *$ \\
\hline 3 & $\begin{array}{l}\text { Will you refer patients to an } \\
\text { Oral and Maxillofacial Surgeon } \\
\text { for reasons other than dentoal- } \\
\text { veolar surgeries in the future? }\end{array}$ & $18.32 \%$ & $13.86 \%$ & $21.29 \%$ & $6.93 \%$ & $9.90 \%$ & $6.93 \%$ & $11.88 \%$ & $6.44 \%$ & $61.40 \%$ & $38.60 \%$ & $0.023^{*}$ \\
\hline
\end{tabular}

their medical colleagues can be expected [9].

In our study, though many participants knew about the existence of the specialty, half of them were ignorant about the procedures performed and unaware that it was not restricted to dentoalveolar surgeries. While a majority of them believed that any surgical specialty should be part of medicine, nearly half of them considered an OMF surgeon to be not sufficiently qualified to perform procedures other than dentoalveolar surgeries. Majority of the participants trusted an OMF surgeon's expertise in performing dental extractions, third molar surgeries, dental implant placement and maxillofacial trauma management while their opinion was split when it pertained to management of TMJ disorders and cosmetic surgeries of the face. A vast majority of the participants did not trust an OMF surgeon's expertise in treating craniofacial anomalies, head and neck cancer and performing microvascular reconstructions. While more than half of the participants had at least once referred a patient to an OMF surgeon, less than half of them had referred for reasons other than dentoalveolar procedures and a majority of them professed to do so only in the future. Our attempt to identify any significant difference in the responses of participants belonging to different designations (viz. undergraduate students, post graduate students, general physicians, specialist practitioners) lead to an innovative finding. The postgraduate and undergraduate students were more aware of the specialty when compared to the general physicians and specialist practitioners and a statistically significant difference was noted in most of their responses $(\mathrm{p}<0.05)$. This could be due to the increasing popularity of multidisciplinary approach to patient treatment which is becoming a part of the current training pattern for the undergraduate and postgraduate students. This could positively influence the awareness and acceptance of the specialty of OMFS in the distant future. 
Apart from the associative finding, the results of our survey are not as surprising, with similar surveys conducted over time proving the relative unpopularity of the specialty in the medical fraternity. This simply shows the unchanging nature of the knowledge, attitude and practice among the medical professionals. As OMF surgeons, we must work towards familirasing the scope of our specialty among the general public as well as among other healthcare professionals. Reddy et al in 2011, discussed the importance of a less complicated and a precisely descriptive name change for the specialty which will easily reach out to the general public. Also, they reiterated the necessity to upgrade the postgraduate training process which will make the young and budding surgeons better equipped and confident to perform non-dentoalveolar procedures [17]. We insist on the same, and in addition, we believe a camaraderie between the medical professionals and OMF surgeons would indefinitely bridge the gap between medicine and dentistry.

\section{Conclusion}

Our study recapitulates the lack of awareness of the specialty of OMFS in the medical fraternity. In a developing country such as India where the awareness and importance given to oral health is yet to improve, it is unrealistic to expect awareness of the specialty among the general public when that of our medical fraternity itself is low. Hence, educating medical students and practitioners about the importance of oral health and more notably the recognition of an OMF surgeon's ability in treating dental and non dental diseases of the cranio-maxillofacial region and unprejudiced referral when needed are crucial and would help to bridge the gap between the medical and dental fraternities.

\section{References}

[1]. Singh V. Sushruta: The father of surgery. Natl J Maxillofac Surg. 2017;8:1-3.

[2]. Tiwari R, Pendyala C, Gurukarthik G, Bhattacharjee A. History of oral and maxillofacial surgery-a review. IOSR J. Dent. Med. Sci. 2017;16:99-102.
[3]. THOMA KH. The history of oral surgery; the oldest specialty of dentistry. Oral Surg Oral Med Oral Pathol. 1957 Jan;10(1):1-10.Pubmed PMID: 13400472.

[4]. Deranian HM. The transformation of the American Association of Oral Surgeons into the American Association of Oral and Plastic Surgeons. J Hist Dent. 2008;56(2):79-86.Pubmed PMID: 18807787.

[5]. Kumar S. Training Pathways in Oral and Maxillofacial Surgery Across the Globe-A Mini Review. J Maxillofac Oral Surg. 2017 Sep;16(3):269-276. Pubmed PMID: 28717283.

[6]. Goodson AM, Payne KF, Tahim A, Cabot L, Fan K. Awareness of oral and maxillofacial surgery as a specialty and potential career pathway amongst UK medical undergraduates. Surgeon. 2013 Apr;11(2):92-5.Pubmed PMID: 23062547.

[7]. Alnofaie H, Alchawaf B, AlKindi M. Knowledge, awareness, and perception of oral and maxillofacial surgery among the public and professionals in Saudi Arabia: a cross-sectional study. Int J Oral Maxillofac Surg. 2019 Dec;48(12):1597-1603.Pubmed PMID: 31248704.

[8]. Farook SA, Rihal K, Abdullakutty A, Coombes D. Lost tribe? Awareness of oral and maxillofacial surgery (OMFS) among the general public. Br J Oral Maxillofac Surg. 2013;51(1):e4-5.

[9]. Subhashraj K, Subramaniam B. Awareness of the specialty of oral and maxillofacial surgery among health care professionals in Pondicherry, India. J Oral Maxillofac Surg. 2008 Nov;66(11):2330-4.Pubmed PMID: 18940501.

[10]. Goss AN, Gerke DC. Effect of training on the scope of oral and maxillofacial surgery. Int J Oral Maxillofac Surg. 1990 Jun 1;19(3):184-9.

[11]. Goss AN, Helfrick JF, Szuster FS, Spencer AJ. The training and surgical scope of oral and maxillofacial surgeons: the International Survey 1994. Int J Oral Maxillofac Surg. 1996 Feb;25(1):74-80.Pubmed PMID: 8833306.

[12]. Nayak K. Oral and Maxillofacial Surgery: It's Future as a Specialty. J Maxillofac Oral Surg. 2011 Dec;10(4):281-2.Pubmed PMID: 23204740.

[13]. Paul G. The future of maxillofacial surgery as a specialty of dentistry. J Oral Maxillofac Surg . 2017 Mar;16(1):1-2.

[14]. Chiu GA, Muff D. International exchange in oral and maxillofacial surgery: comparison of the training pathways in the UK and USA at the end of the twentieth century. Br J Oral Maxillofac Surg. 2001 Dec 1;39(6):465-70.

[15]. Ginzberg E, editor. Health services research: key to health policy. Harvard University Press; 1993.

[16]. Hunter MJ, Rubeiz T, Rose L. Recognition of the scope of oral and maxillofacial surgery by the public and health care professionals. J Oral Maxillofac Surg. 1996 Oct;54(10):1227-32.Pubmed PMID: 8859242.

[17]. Reddy K, Adalarasan S, Mohan S, Sreenivasan P, Thangavelu A. Are people aware of oral and maxillofacial surgery in India?. J Oral Maxillofac Surg. 2011 Sep 1;10(3):185-9. 